\section{La mujer como sujeto activo del acceso carnal}

The woman as active subject of carnal

access

José Ángel Bonilla-Coneo' - Leslie Ujueta-Marmoleio

\author{
ACEPTAD0: 27-06-16
}

Resumen

Este artículo es un análisis jurídico, cuya finalidad es exponer el problema sobre la delimitación del hombre como sujeto pasivo del acceso carnal en alguna de sus modalidades contempladas en nuestro Código
Penal, debido a los vacios o lagunas existentes en el ordenamiento juríico colombiano en cuanto al tema Se necesita de manera urgente establecer pautas para definir prolijamente el tipo de acceso carnal, con ser el sujeto activo y, de no ser asi, al momento en que se presenten situaciones de esta envergadura, lo más probable es que sean solucionadas con dudosas bases juridicas y argumentativas que carecerían de

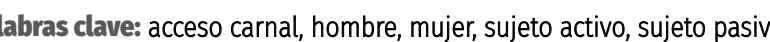

Abstract

This article is a legal analysis, whose purpose is to expose the problem of the delimitation of man as a gaps in the Colombian legal system in about the subject.

It is urgently necessary to establish guidelines to define the type of carnal access in order to eradicate from our legal environment that failure to believe that man should be the active subject and, if not, at the moment present situations of this magnitude, they are most likely to be solved with dubious legal and

eywords: access carnal, man, woman, subject active, subject passive.

Estudiante de noveno semestre de Derecho de la Universidad de Caragaena, miembro del Semiliero Germinación-Tutela Penal

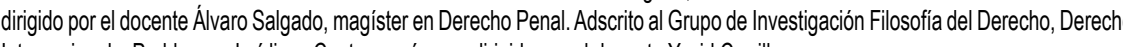
Intiemacional y Problemas Juridicos Contemporáneos, dirigido por e I locente Yezid Carril

Estudiante de octavo semestre de Derecho de la Universidad de Caragena, miembro del Semilitero Germinación-Tutela Pena

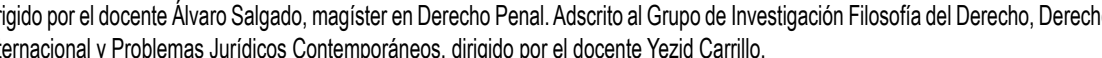
lesileyjueta_04@hotmail.es
Observamos que el fundamento jurídico vigente, no emite un concepto claro sobre el alcance del acceso carnal, por lo que resulta necesario un pronto análisis, regulación o reforma, en aras de examinar cualquier posible inconsistencia y plantear soluciones en relación a estos, evitando que se vea afectada la seguridad jurídica del Estado colombiano.

Lamentablemente, son pocas las investigaciones académicas en Colombia sobre la incidencia de aquellos delitos sexuales donde el hombre es el sujeto pasivo. Anhelamos que esta exploración sea la punta de lanza para que los estamentos sociales, doctrinales, académicos y jurisprudenciales empiecen a indagar y se vean obligados a actuar proactivamente a favor del tema. Es un hecho cierto e irrefutable que los mecanismos y herramientas acerca del tema en específico son escasos y lo poco aportado por parte de la doctrina y los juristas no responden a la cosmovisión esperada.

El objetivo del presente documento es analizar la precedencia histórico-jurídica del acceso carnal en variedad de sus formas, se examinará cuidadosamente los criterios doctrinarios al respecto, posteriormente se emitirá una posición a favor o en contra de la presente cuestión y los factibles vacíos legislativos en relación a la conducta de quien accede carnalmente y quien es accedido, ya que se presta para múltiples interpretaciones jurídicas la endeble concepción normativa del acceso carnal. Es por ello que mediante esta investigación se tratará de determinar la manera cómo estos casos deberán ser concertados.

Se analizará en el ordenamiento jurídico colombiano hasta qué punto se propende por una protección especial al hombre en su calidad de sujeto pasivo de aquellos delitos mencionados anteriormente, la información que se tomará como base es de carácter secundario y girará en torno de la siguiente pregunta problema, ¿de qué manera se ha desarrollado el principio de la protección especial a los hombres en su condición de sujeto pasivo del acceso carnal?

\section{METODOLOGIA}

Nos encontramos frente a una indagación eminentemente jurídica, de tipo analítico-documental, la cual contará con un enfoque de carácter cualitativo puesto que es menester apoyarse en antecedentes legales, decisiones 
jurisprudenciales, el dogmatismo teórico y el Derecho Comparado. El método de investigación es deductivo, que se desarrollará con apoyo de otras disciplinas que complementan los supuestos fácticos del Derecho.

El desarrollo del presente sondeo se justifica en el contexto descrito, de modo que denota el peligro en que se encuentra estructurada tipológicamente la descripción normativa del acceso carnal frente a la realidad.

\section{FUNDAMENTO JURÍDICO Y GRAMATICAL DE ACCESO CARNAL}

Acceso, según el Diccionario de la Real Academia Española, es un sustantivo que significa "Entrada o paso", esta es la idea central del concepto, sin desconocer aquellas acepciones del término que giran alrededor de ella (Entrada al trato o comunicación con alguien, coito, etc.). Pero el término acceso, sin dejar de ser sustantivo, debemos analizarlo desde el campo de la acción, al ser potencial del verbo acceder, la cual va más encaminada a la extensión de penetrar, introducir y meter.

Profundizando un poco más en la materia, cuando nos referimos específicamente al acceso carnal como tal, la esfera de protección normativa advierte que la finalidad de este delito es salvaguardar a aquel individuo de aquella violación a la que puede ser sujeto pasivo tanto la mujer como el hombre, violación que atenta contra la disponibilidad erótica de su cuerpo.

Según el Código Penal colombiano en su artículo 212, el acceso carnal hace referencia a "la penetración del miembro viril por vía anal, vaginal u oral, así como la penetración vaginal $o$ anal de cualquier otra parte del cuerpo humano u otro objeto"; de esta definición se observan varios componentes que es necesario analizar detalladamente para poder comprender todo lo que encierra o abarca su interpretación normativa.

La definición de acceso carnal trae consigo ciertos enigmas que al intérprete de norma le corresponde resolver, situación espinosa al momento de entender dicho concepto puesto que cada ser humano es diferente y el razonamiento nos puede llevar a pensar de múltiples maneras y no es apropiado para el Derecho dejar en manos del juez o togado de turno la subjetividad a la hora de resolver la controversia sobre la que versa el juicio.
Por esa razón, es un texto abierto que al momento de abordar la exégesis gramatical de la norma se presentarian per se inconsistencias en los operadores jurídicos a la hora de aplicar el tipo y establecer su repercusión.

Su descripción normativa nos invita a generar comentarios como por ejemplo: "solamente puede acceder carnalmente el hombre", "la mujer nunca puede ser sujeto activo del acceso carnal al no poseer miembro viril", "una vagina no puede penetrar", cuando objetivamente la norma no expresa taxativamente lo anterior

En relación a lo manifestado, apreciamos que es pertinente enfatizar en el criterio gramatical, recurriendo al método sistemático de la interpretación de texto e incluir en la descripción de la norma la importancia del órgano sexual. El artículo 212 fue creado con el objetivo de eliminar controversias legales existentes sobre el concepto, sin embargo, continuamos con el mismo vacío sobre el sujeto activo.

Normativamente sería más idóneo hablar de "aparato reproductor" en lugar de miembro viril, debido a que un numeroso sector de la doctrina considera al hombre como el único dotado de la aptitud fisiológica para conjugar el verbo rector, no obstante, el artículo 212 deja abierta la controversia, argumento que es omitido.

\section{DEFINICIÓN NORMATIVA DEL ACCESO CARNAL Y OTRAS MODALIDADES}

El artículo 205 del Código hace alusión en virtud del acceso carnal violento como aquel que se realiza "con otra persona mediante violencia", noción bastante simple y que debe ser complementada con el artículo 212A que aclara apropiadamente el concepto de violencia que exige el tipo penal:

Se entenderá por violencia: el uso de la fuerza; la amenaza de uso de la fuerza; la coacción física o psicológica, como la causada por el temor a la violencia, la intimidación; la detención ilegal; la opresión psicológica; el abuso de poder; la utilización de entornos de coacción y circunstancias similares que impidan a la víctima dar su libre consentimiento.

Dicho lo anterior, es evidente que el acceso carnal violento como su mismo nombre lo indica exige la violencia como un elemento descriptivo de la 
conducta del sujeto activo del injusto, aparte, es necesario que el agente del delito tenga un ánimo libidinoso y lúbrico, acompañado por el deseo sexual ervoroso que transgrede la libertad e integridad del sujeto pasivo de la conducta quien no da su consentimiento sobre el acto que se está realizando sobre su cuerpo, por el contrario, está siendo obligado mediante la coacción.

Desglosando minuciosamente la clasificación tipológica del acceso carnal violento, vemos que es de resultado naturalístico, para que la conducta se configure, se requiere que haya resultado fáctico, es un tipo de lesión al contener en el mismo, un resultado lesivo del bien jurídico tutelado, mono ofensivo, de conducta instantánea en virtud de que la acción debe agotarse en un solo momento. Por otra parte, correspondiente a la conducta descrita, contiene un verbo rector determinador simple: "Realizar" y por último, es posible afirmar que tanto el sujeto activo como el pasivo, son singulares e indeterminados, sustento claro para continuar afirmando que el hombre puede ser víctima de este tipo penal.

\section{DIVERSAS FORMAS DE ACCESO Y ACTO SEXUAL VIOLENTO Y/O ABUSIVO}

En efecto, está claro que nuestro presente estudio atiende netamente al acceso carnal violento y, demás delitos sexuales apreciados en el Titulo IV Capítulo Primero del Código Penal que lleva por título "De la violación"; empero contemplamos oportuno abordar del Capítulo Segundo, el tipo penal referente al acceso y/o actos sexuales abusivos con menor de catorce años, con base en ciertas situaciones que a continuación plantearemos.

Respecto al acto sexual violento, el Código Penal colombiano en su artículo 206 declara que hace referencia a "el que realice en otra persona acto sexual diverso del acceso carnal mediante violencia", como observamos, esto no es propiamente una definición, ya que, es un texto muy abierto y no es posible establecer su alcance.

Tal como lo ha dicho el doctrinante Orts (1995): "entre el acto y la fuerza ha de haber conexión causal, de modo que sea lícito establecer que el primero se ha producido como consecuencia de haberse usado la segunda" (p.74).

En cuanto a su clasificación tipológica, es igual a la desglosada con anterioridad cuando nos referimos al acceso carnal violento, no existe discusión en virtud de que tanto el sujeto activo como el pasivo son indeterminados, el inconveniente encontrado es incurrir en un yerro jurídico al pensar que ciertas conductas realizadas por una mujer claramente determinadas en la descripción de acceso carnal violento sean resueltas o adecuadas típicamente como actos sexuales violentos.

Apoyamos nuestra hipótesis en un ejemplo ilustrativo planteado por el distinguido tratadista Agudelo (2010), a continuación citaremos dicho acontecimiento:

Sujeto $X$ en compañía de mujer $Y$ deciden mediante violencia atar de sus brazos y piernas a hombre $Z$, posteriormente el sujeto $X$ introduce su pene en la boca del sujeto $Z$, luego, mujer $Y$ realiza la misma acción pero con su vagina. (p.69)

Con el ejemplo traído a este cotejo, es irrazonable que los eruditos del Derecho consideren que el sujeto $X$ es responsable penalmente por el delito de acceso carnal violento y que la mujer $Y$ deba ser procesada por acto sexual violento siendo asi traemos el siguiente planteamiento, ¿por qué adecuar típicamente en opuesto sentido dos conductas totalmente iguales? Está claro que ambos introducen sus órganos reproductores sobre la boca del sujeto $Z$ y a nuestro juicio a ambos se les debe atribuir el delito de acceso carnal violento. ¿Dónde queda el principio de igualdad en materia penal?

Ahora bien, entrando en el acápite del artículo 207 del Código Penal colombiano contemplado en su nomen luris como "Acceso carnal o acto sexual en persona puesta en incapacidad de resistir", este tipo penal protege la libertad e integridad de aquella persona puesta en incapacidad de resistir o en estado de inconsciencia, o en condiciones de inferioridad síquica que le impidan comprender la relación sexual o dar su consentimiento.

El tema en cuestión referente al sujeto pasivo, por la descripción tipológica estructurada nos faculta para afirmar que puede ser cualquier Individuo de la especie humana vivo, hombre o mujer, quien en virtud del actuar delictivo del agente haya quedado en incapacidad de resistir, en estado de inconsciencia o en condiciones de inferioridad psíquica.

Muy a pesar de que la situación mencionada resulte poco común o inusual, los registros demuestran que tales casos se han presentado en diferentes países, por ejemplo, en Inglaterra, según informa el diario británico Daily Mail (2015) 
tres mujeres accedieron de manera carnal a un hombre; mediante violencia y apuntándolo con un arma fue empujado y obligado a ingresar a un automóvil en el que fue transportado, forzado a tomar una sustancia desconocida y por último consumaron el acceso carnal al este no ser consciente de sus actos.

En definitiva, tenemos como hipótesis que una mujer puede obligar al hombre o provocar su estado de inconsciencia o de inferioridad psíquica mediante el uso de sustancias idóneas como narcóticos, somníferos, alucinógenos, escopolamina, viagra, afrodisíacos, etcétera. Erecto el hombre a causa de la conducta desplegada por la mujer, será sencillo para esta provocar el acceso carnal y el hombre no sería consciente de su respuesta sexual.

Inmiscuyéndonos en el terreno de aplicación de los actos sexuales abusivos, ocaremos inicialmente el artículo 208, "Acceso carnal abusivo con menor de catorce años", en el entendido de que una de las características principales de estos delitos abusivos radica en que no es requisito sine qua non la violencia dentro del tipo.

La cuestión que pretendemos abordar es el tratamiento normativo que se le ebe brindar a un acceso carnal cometido por una mujer con un menor de 14 años en donde este presta su consentimiento que como bien sabemos, aquí no es determinante en razón de que ellos no cuentan con libertad sexual, es un consentimiento viciado.

En esta situación, ¿quién accede carnalmente a quién? Otro evento fáctico que presentamos en forma de interrogante arraigado en ipuede una mujer mayor de edad incurrir en un error de tipo (vencible o invencible) al sostener relaciones sexuales consentidas con un menor de 14 años que aparenta mayor edad pero en realidad tiene 13 años? Todos estos cuestionamientos van encaminados a valorar tantas situaciones que se pueden presentar en torno a la mujer como sujeto activo del acceso carnal y acto sexual violento y/o abusivo con menor de 14 años.

Recientemente, por medio del periódico El Tiempo (2017) se hizo viral a finales del 2016 el caso ocurrido en Estados Unidos, concretamente en el Estado de Texas el juez estatal Michael McSpadden condenó a diez años de prisión una maestra de 24 años docente en el área de Idiomas, quien sostenía frecuentemente relaciones sexuales consentidas con un adolescente de 13 años en Houston, Estados Unidos y producto de sus encuentros sexuales ella quedó en embarazo. Esto nos indica que ya se están presentando desde hace cierto tiempo estas situaciones en el mundo y que el ordenamiento jurídico colombiano debería tomar como precedente estos casos y restablecer el procedimiento empleado.

Por último, mencionaremos el delito de "Acceso carnal o acto sexual abusivo con incapaz de resistir", artículo 210 del Código Penal para establecer las mínimas diferencias con el artículo 207 "Acceso carnal o acto sexual en persona puesta en incapacidad de resistir". La diferencia principal está en que no es igual que la victima haya sido puesta en incapacidad de resistir o en estado de inconsciencia a que sea un incapaz de resistir biológicamente y que por ejemplo padezca un trastorno mental desde corta edad. En el artículo 207 el agente crea y organiza la situación colocándolo en condiciones de inferioridad, mientras que en el artículo 210 el agente se aprovecha de dichas condiciones naturales y en ninguno de los dos es necesaria la violencia.

\section{DISCIPLINAS CIENTIFICAS AUXILIARES}

\section{Psicologia}

Para la Psicología, la sexualidad representa un conjunto de fenómenos funcionales y del comportamiento, condicionados culturalmente independientes de la función reproductora, que se manifiestan en el hombre y en la mujer como respuesta a los estímulos sexuales de cualquier tipo, y que tienden a llevar al individuo a la unión placentera física o emocional consigo mismo o con el objeto externo, pero generalmente con otra persona.

Los daños psicológicos causados por una violación son irreversibles, sus consecuencias pueden ser tan tenebrosas que perduran por mucho tiempo según estudios psicológicos, el $80 \%$ de las víctimas de abusos sexuales evidencia sintomas negativos después de un año de la embestida contra su libertad sexual.

Es tan traumático y engorroso el tema que las reacciones pueden ser de diversa indole, desde sentimientos de culpa, desconfianza, ira, temor, baja autoestima e inclusive, deseos de acabar con su victimario y vergüenza propia. Esto no es todo, de igual manera puede presentar sensaciones depresivas, sufrir de ansiedad, estrés, adicción a sustancias y tristemente, puede desencadenar en un suicidio. 
Todo ser humano que ha padecido una violación necesita asistencia psicoterapéutica, son acontecimientos que han quedado en la psiquis humana y que necesitan suficiente tiempo y ayuda externa para su manejo y evolución eficaz, es ahí donde el profesional idóneo para tratar estos temas proporcionará apoyo y las herramientas necesarias para superar este lamentable hecho.

\section{Criminologia}

El ilustre jurista y criminólogo Garofalo (2005), exponente de la Escuela Positiva italiana, cuyo mayor aporte a esta fue su teoría del delito natural, el cual definió como la "lesión de aquella parte de los sentimientos altruistas fundamentales de piedad o probidad, en la medida en que son poseídos por una comunidad, y que es indispensable para la adaptación del individuo a la sociedad". El hecho de fundamentar la responsabilidad penal en la temibilidad o peligrosidad del delincuente y no en el libre albedrío.

Otro punto importante para destacar del autor es su concepción del delito como un hecho natural, fenómeno humano influenciado por causas endógenas tales como alcoholismo y la drogadicción, el consumo habitual u ocasional que puede estimular o desinhibir la conducta violenta; La tendencia a la frustración-sensación de fracaso, abandono o rechazo. Causas sociales como la escasez 0 falta total de valores o principios rectores del propio comportamiento, el aprendizaje por modelación o sublimación de conductas violentas o predisposición a estados pasionales-emociones intensas, etc. Estas variables psicológicas-criminológicas pueden adquirir el carácter de psicopatías que impulsan a la comisión de un delito.

\section{SOPORTE DOCTRINARIO QUE RECONOCE LA PROBABILIDAD DE LA MUJER} COMO SUJETO ACTIVO DEL ACCESO CARNAL Y ARGUMENTOS OPUESTOS

Tradicionalmente, gran parte de la doctrina llegó a afirmar que el acceso carnal violento implicaba la intromisión viril por cualquiera de los esfínteres de la víctima. Apoyado en lo anterior, la tesis argumentativa pretendía que solo el hombre pudiera ser sujeto activo, la mujer siempre sujeto pasivo y de ninguna manera activo.

Como lo expone Barrera (1963), solo puede realizar la conducta típica quien penetra, es decir, el hombre. Sostiene que es muy complejo en términos fisiológicos que el hombre bajo coacción, temor y violencia alcance los grados necesarios de erección y mucho más arduo, logre la penetración, por ende, al alcanzar altos grados de erección estaría consintiendo el acto.

Además, los defensores de la teoría del acceso carnal solo en mujeres respaldaron su premisa sosteniendo que un hombre solo podría ser accedido por la vía anal por otro hombre, porque quien está accediendo cuenta con el miembro viril que exige el tipo penal y quien está siendo accedido es sometido por una de las formas de acceso carnal basada en la penetración anal.

En oposición a lo anterior, Garrido (2005) considera factible los postulados que apoyan la alta probabilidad de ser la mujer sujeto activo del acceso carna violento, designándola como una Violación Inversa, hipótesis de violación a un hombre por parte de una mujer, en la cual esta mediante violencia obtiene la penetración del órgano viril de aquel.

Como ya se explicó, una de las formas de violencia es la apodada violencia física, es necesario traer a colación un ejemplo reiterado por la doctrina, el cual se fundamenta en que una mujer posee un arma de fuego y con esta intimida a un hombre diciéndole "accédeme o te quitaré la vida, el hombre atemorizado ante la coacción ejercida por la mujer cumple sus órdenes", lo anterior nos lleva a formular el siguiente interrogante, ¿quién es el sujeto activo del acceso carnal violento y quién es el sujeto pasivo en el presente caso?

Porte (1991) nos enseña que la mujer puede ser sujeto activo de la violación mediante violencia, tanto física como psicológica, puesto que puede lograrse la mecánica del coito con el hombre venciendo los obstáculos fisiológicos para la erección del órgano masculino.

Carnevali (2001) reflexiona y de lúcida forma alega igualmente que la muje es sujeto activo del delito de violación, pero sus razones difieren con el auto anterior. Indica que para arribar a ese término es necesaria la interpretación pero no con un criterio formalista que habla sobre la gramática legal, sino más bien cimentado en el aspecto teleológico, teniendo en cuenta el fin de la ley, lo cual es posible deducirlo si se tiene en consideración el principio político-criminal de la protección a los bienes jurídicos. 
Así, seria extensa la lista de doctrinantes y juristas que defienden su postura. Lo que si es claro es el vacío que se ha manejado en el sistema penal colombiano en cuanto a este tema, que en lo más posible intentaremos resolver.

\section{EL HOMBRE COMO SUJETO ACCEDIDO}

Se cree que cuando el hombre no se encuentra erecto es imposible que penetre, pero si logra un estado de excitación da a entender que consiente dicho acto, lo cual no configuraría un ilícito. Empero, olvidan el placer que siente el hombre cuando se genera el estímulo sexual, a pesar de oponerse, tan solo con un contenido adecuado de andrógenos circulantes en los genitales masculinos, puede derivar un estado plácido de excitación no voluntario, esto a partir de los estímulos táctiles directos, de su propia biología y la reacción natural del cuerpo ante el contacto.

El estímulo directo del orden táctil, es considerado el primer inductor de la excitación sexual, la rapidez con la que se puede alcanzar la excitación depende de la naturaleza y asimilación del estímulo aplicado, lo cual produce el aumento de la tensión sexual hasta llegar a un punto vértice o culminante.

La estimulación sexual generada por el contacto entre la vagina y el pene adquiere determinados grados de intensidad y permanencia, y la tensión sexual se incrementa poco a poco.

También, desde un punto de vista fisiológico la erección es causada por la vasodilatación sanguínea de origen arterial o estimulación de los nervios espásticos y que biológicamente finaliza en la eyaculación producto de un reflejo neuro-vegetativo y no puede ser controlada psíquicamente.

En los casos de hiperclitorismo (hipertrofia de clítoris) o clitoromegalia, definido como el aumento anormal del clítoris, existe la probabilidad de que la mujer pueda realizar el acto de penetración en el hombre, hipótesis realizable y que a su vez lo podría lograr penetrando oralmente, siendo esta una de las formas de acceso carnal, tratándose de introducción del clítoris desarrollado y esto en el caso específico puede ocurrir, aunque también podría acontecer que la solución normativa sea desacertada y esta acción la encajen en acto sexual violento.
El acceso carnal se refiere en forma exclusiva al "miembro viril" en el artículo 205, pero sin duda, el clítoris hace parte de esa "cualquier otra parte del cuerpo humano" apta e idónea para acceder a la que se refiere el artículo 212 Por lo tanto, que la mujer no cuente con miembro viril no denota que esté excluida para ser sujeto activo del tipo, al encontrarse el clítoris capacitado para ejecutar el verbo rector penetrar.

Así las cosas, queda aún más respaldada nuestra inclinación, el artículo 205 exterioriza "el que", es decir, refleja lo indeterminado y singular que puede ser el sujeto activo tanto el hombre como la mujer, de lo contrario la norma ordenaría taxativamente "el hombre que" o "la mujer que". De igual manera ante la expresión "con otra persona" la norma manifiesta que puede ser el sujeto pasivo indeterminado, distinto es si enunciara "con una mujer mediante violencia".

De esta manera, no se quebrantaría el principio de Tipicidad ni mucho menos el de Legalidad en el evento en que se presente un acceso carnal violento cometido por una mujer, puesto que es posible adecuar típicamente este delito al estar contemplada su existencia y posibilidad en la descripción normativa, la cuestión sería examinar por parte del operador jurídico la problemática que acarrean los tipos penales abiertos o cerrados, enigma que debe ser considerado por los respetados jueces y magistrados de la República, el problema no es precisamente lo que diga la norma, el punto de referencia está en la interpretación que se le dé a la misma por parte del togado.

Es inconcebible que en pleno siglo XXI, en un mundo globalizado y con tantos avances tecnológicos muchos consideren como un tabú o superstición que un hombre pueda ser accedido carnalmente por una mujer. Probablemente esta parte de la población se apoya en los comentarios mayoritarios para no ir en contra de la multitud y peor aún de la sociedad, en este sentido, que sea una parte reducida los que consideremos lo contrario, no quiere decir que no sea evidente la realidad, por esta razón perseguimos arrebatar la venda de sus ojos, es hora de despertar.

Real protección del ordenamiento jurídico colombiano a la libertad e

\section{integridad sexual del hombre como sujeto pasivo del acceso carnal}

La sociedad colombiana se ha caracterizado por sus altos grados de machismo y autoridad masculina, nadie desconoce que nos encontramos en un territorio 
altamente polarizado por una cultura que observa al hombre por naturaleza superior a la mujer, se concibe a este como un ser dominante en la sociedad y en las relaciones de pareja, razón por la cual el legislador sabiamente ha procurado reforzar la protección especial de la mujer; este mensaje ha sido transmitido legalmente como apoyo y tutela de aquellos derechos y prerrogativas que gozan las mujeres en la sociedad, un claro ejemplo de esto fue la puesta en marcha de la figura garantista del feminicidio y sus agravantes en nuestro Código Penal.

No obstante, la igualdad y las garantías judiciales siempre deben permanecer como un equilibrio social, el hombre no puede encontrarse desprotegido legalmente en un tema tan trascendental como lo son los delitos sexuales, la mujer no debe lucir con mayor respaldo, las cargas deben ser equilibradas en un Estado proteccionista. Consideramos que el sexo masculino jamás debe pasar a un segundo plano a la hora de establecer el camino de un acceso carnal, quizás esto se presenta a causa del afán de regular un asunto que frecuentemente se presenta en mujeres como víctimas, pero se dejó a un lado al hombre dentro de la regulación de este tipo penal.

Uno de los primeros pronunciamientos de nuestra excelsa Corte Constitucional colombiana sobre este tema fue enunciado en la Jurisprudencia C-285 (1997) fundadora de Derecho, donde se expone lo siguiente:

La sanción de las conductas de violación parte del reconocimiento del derecho a disponer del propio cuerpo, y constituyen un mecanismo tendente a garantizar la efectividad del mismo. Hoy, debe aceptarse que tanto el hombre como la mujer pueden ser sujetos pasivos de violencia sexual. (p.2)

Siendo la Corte Constitucional el órgano de cierre por excelencia de la jurisdicción constitucional, resulta fructífero que estime acertadamente la alta probabilidad del hombre como sujeto pasivo de acceso carnal y al mismo tiempo desarrolle la temática relativa a la sexualidad y su notable relevancia.

De ahí, la sexualidad es tan importante que constituye una función o actividad del ser humano como resultado de la conjunción del desarrollo biológico, funciones somatofisiológicas básicas y del medioambiente sociocultural, que asume dos objetivos esenciales y que no revisten la misma trascendencia: la reproducción y la satisfacción sensitiva. Por esto, la sexualidad es función reproductiva y erótica, fruto del proceso evolutivo biológico.

Desde entonces, la sexualidad hace parte intrínsecamente de nuestra personalidad e identidad, es decir, el aspecto psicológico de esta y al mismo tiempo es una de las necesidades humanas que se expresa a través de cuerpo, es parte del deseo y placer para la satisfacción personal y estimula la necesidad constante de establecer relaciones interpersonales con otros.

Históricamente, desde el Derecho Romano el delito de violación sexual era una especie de los llamados "delitos de coacción", siempre se llamó o se discutía el aspecto femenino de la violación: "si la acción era realizada sobre una mujer virgen, casada, viudas, religiosas", a saber, ¿alguna vez fue motivo de discusión u objeto de análisis una violación masculina? en suma, este tema comenzó a ser planteado siglos posteriores.

Como es bien sabido, la religión católica, impuso aquel conjunto especial de normas o imperativos comportamentales en íntima relación con lo espiritual que define la sexualidad exclusivamente a la concepción procreativa, que tan solo podía verificarse dentro del matrimonio, de lo cual emerge el deber moral de abstinencia sexual, según para no ir en contra de los designios divinos. Es por ello que para la religión, la sexualidad no es una función esencial del ser humano, sino un acto de maldad y desviación, tolerable única y exclusivamente, si por medio de su ejercicio se alcanza la finalidad procreadora de la especie.

De cualquier modo, teniendo en cuenta que el hombre es un ser con principios y valores arraigados, que van de una generación a otra, influenciado por la religión y la sociedad en sí, igualmente, todo aquello que se encuentre en el medioambiente en donde convive, resultaría ofensivo, grave y hasta degradante para él, en el hipotético caso de que su cuerpo como tal fuera vejado, violentado o ultrajado convirtiéndose en el sujeto pasivo de una conducta lujuriosa y libidinosa.

En ese orden de ideas, ¿qué pasaría dado el caso de aquel hombre sumamente creyente en los designios divinos, acogido a la idea de castidad y pureza hasta el matrimonio, considerando este como el momento oportuno para disfrutar plenamente de su sexualidad con la persona amada, en pro a su autonomía 
como persona?, ¿qué tan relevante es esta interferencia que aligera y precipita dicho momento significativo para su vida?

Con el solo hecho de ser accedido carnalmente, el hombre puede padecer emociones y sentimientos pérfidos, aniquiladores de esa libertad sexual que tanto ha pretendido proteger, atrás quedaría esa facultad del ser humano de autodeterminar y autoregular su vida sexual, de elegir y aceptar. Sería un completo rechazo al reconocimiento de la dignidad de la persona violentando el respeto por su integridad, básico para entender la determinación del presente objeto jurídico.

\section{Incidente de reparación integral}

En un ordenamiento jurídico como el colombiano donde la concepción social que se tiene sobre la justicia es paupérrima y la confianza en el sistema es mínima, debido a la alta corrupción de la organización política y jurídica del Estado. Primeramente, gozan de poca eficacia y credibilidad los mecanismos creados por la ley para proteger aquellos derechos fundamentales de la sociedad y cabalmente en el ámbito penal, existe recelo y escepticismo por los instrumentos legales con que cuentan las víctimas de los delitos descritos a lo largo del extenso Código Penal, entre ellos los delitos sexuales.

A pesar de esto, el incidente de reparación integral es el único artilugio con que se cuenta si se pretende el resarcimiento de los perjuicios ocasionados como víctimas del ilícito. La Honorable Corte Constitucional colombiana en Sentencia C-059 (2010) desarrolla holgadamente este concepto desde una perspectiva amplia y estructurada que seguidamente nos permitimos traer el siguiente aperitivo: "El incidente constituye una primera oportunidad judicial como posición jurídica definitiva para hacer efectivo el derecho a la reparación integral de la víctima que, prima facie, contempla la Constitución" (p.1).

ncluso, constituye la oportunidad indicada de poner en marcha el derecho de acceder a la justicia y velar porque se garantice plenamente aquella Justicia Restaurativa como mecanismo constitucional y como acción de reparación integral, que es también acción civil, al final del proceso penal, una vez declarado un sujeto penalmente responsable y la providencia quede ejecutoriada materialmente.
Del mismo modo, la reparación integral comprende varios componentes inherentes a sus fines, por ejemplo la reparación material, moral, simbólica, entre otras. Se busca el resarcimiento efectivo de la víctima respecto a los perjuicios ocasionados con el delito.

Está claro que la víctima de un acceso carnal jamás podrá restaurar su entorno social y personal de forma idéntica a como se encontraba antes del fatídico acontecimiento, pero creemos que con el incidente de reparación integral el Estado Social de Derecho, concretamente el Sistema Penal Acusatorio colombiano incentiva y estimula su presente con el resarcimiento de los daños o quebrantos vividos y a través de su política criminal crea y ejecuta las pautas necesarias para no empeorar en lo posible la convivencia de la persona afectada.

\section{DERECHO COMPARADO}

Comprendemos que cada ordenamiento jurídico es diferente en razón a conjunto de normas jurídicas que lo gobiernan en ese lugar determinado y en aquella época específica. De la misma manera, el tratamiento que se le brinda a los delitos sexuales, más precisamente el de violación es diferente en algunos Estados, otros son muy similares en sus apreciaciones sobre el tema.

\section{Argentina}

En primer lugar tenemos el caso de Argentina. El delito de violación se encontraba reglamentado en dicha legislación bajo el Titulo de "delitos contra la honestidad" que en su artículo 119 afirmaba: "Será reprimido con reclusión o prisión de seis a quince años, EL QUE tuviere acceso carnal con persona de uno u otro sexo en los casos siguientes (...)".

El artículo recién mencionado fue derogado por la Ley 25.087, promulgada con fecha 07 de mayo de 1999, señalando la nueva normativa lo siguiente: Artículo 119: "Será reprimido con reclusión o prisión de seis meses a cuatro años, EL QUE abusare sexualmente de persona de uno u otro sexo (...)"

\section{Perú}

A su vez, el Código Penal peruano aprecia el delito de violación en los artículos 170 y siguientes de su cuerpo legal: "el que con violencia o grave amenaza 
obliga a una persona a tener acceso carnal por vía vaginal, anal o bucal o realiza otros actos análogos introduciendo objetos o partes del cuerpo por alguna de las dos primeras vías (...).

\section{Chile}

En el Estado chileno, el delito de violación, luego de las modificaciones introducidas por las Leyes 19.617 y 19.927, se encuentra definido en los artículos 361 y 362 del Código Penal, cuyo texto es el siguiente:

Artículo 361: “La violación será castigada con la pena de presidio mayor en su grado mínimo a medio. Comete violación el que accede por vía vaginal, anal o bucal, a una persona (...)"

\section{Panamá}

El Código Penal de la República de Panamá en su Titulo III Capítulo I que leva por nombre "Violación y otros delitos sexuales", más precisamente a partir del artículo 174 y sus siguientes que citaremos a continuación: "Artículo 174. Quien mediante violencia o intimidación tenga acceso carnal con persona de uno u otro sexo, utilizando sus órganos genitales, será sancionado con prisión de cinco a diez años".

Después de hacer el estudio correspondiente de las distintas legislaciones atinas en cuanto al tema tratado, queda en evidencia las semejanzas a la hora de tratar las diversas descripciones de los tipos penales, teniendo en común el mismo verbo rector "acceder carnalmente" y coinciden en que el acceso carnal puede realizarse vía anal, oral y vaginal.

Si bien es cierto, el único capaz y apto para cometer el ilícito es el hombre atendiendo la estricta fórmula de "acceder carnalmente", es importante puntualizar el encabezado con el que inicia la mayoría de las descripciones típicas: "el que" "dejando una puerta abierta a la interpretación de que no siempre sea el hombre el activo del tipo, sino que se optó porque fuera indeterminada la persona que realice la conducta.

La característica que más se resalta en la mayoría de ordenamientos jurídicos tanto en América Latina como en los países más representativos de Europa estriba en que el tipo penal exige la violencia ineludiblemente, además, aunque la norma no lo exprese, está claro que se necesita el ánimo libidinoso o lujurioso dirigido a consumar el acceso carnal violento; sin embargo, resaltamos los Estados de Panamá y Argentina, quienes precisaron un poco más en el asunto y distinguen dentro de la descripción del tipo penal "Con otra persona de uno u otro sexo", concretando con más especificidad el sujeto activo indeterminado del delito.

El Código Penal panameño trae consigo otra demostración aún mucho más clara al hablar de penetración de los "Órganos genitales" y no limitarse como lo han hecho muchos países incluyendo el nuestro, que cierran el acceso carna y se quedan cortos con la acepción "Miembro Viril" que encaja solamente en el aparato reproductor masculino, es una gran innovación los presupuestos descriptivos del Código Penal panameño.

\section{CONCLUSIONES}

En suma, luego de abordar cuidadosamente la temática del acceso carnal cometido por una mujer en todas sus modalidades, apreciamos pertinentemente afianzar nuestras consideraciones motivadas por la completa convicción de que una mujer claramente puede ser sujeto activo y el hombre sujeto pasivo del acceso carnal, ya que como se demostró, así como el hecho de que una mujer eyacule no es sinónimo de consentimiento y por ende no tipicidad de un acceso carnal, la acción de excitación y erección del hombre, no es significado que esté disfrutando y/o consintiendo el acto delictivo, configurando el tipo penal y por añadidura, siendo sujeto pasivo de este.

En todo caso, los tipos penales abiertos o cerrados no pueden ser excluyentes y mucho menos en un tema de tanta envergadura, el criterio gramatica empleado en ellos debe ser muy preciso. Observamos la carencia de criterio en razón a que no se encuentra evolución normativa sobre el tema a partir del Código Penal de 1837, pasando por los Códigos de 1873, 1936, 1980 y en el actual, puesto que con la implementación de la Ley 599 del año 2000, uno de los objetivos principales del artículo 212 era regular el asunto de fondo al determinar conceptualmente qué encaja en el acceso carnal y qué no hace parte del mismo, justamente para evitar controversias doctrinales y jurisprudenciales al respecto, no obstante, el vacío legal está vigente, justamente es la motivación principal para elaborar el presente proyecto. 
Consideramos idóneo para la preservación de las garantías y protección judicial en igualdad de armas y sin presunciones ambiguas, la inclusión ya sea en la descripción de la norma (artículo 205 y sus siguientes) 0 en la definición del Acceso Carnal (artículo 212) la importancia del órgano sexual como lúcidamente lo estableció el Código Penal panameño cuando nos habla de "Órganos Genitales", o implementar otra parte de su descripción normativa que reza "con otra persona de uno u otro sexo" esta consideración sería muy eficaz y si ligado a esto se adiciona la expresión "aparato reproductor" quedaría completamente claro para el intérprete de la norma el espíritu de la ley, zanjándose los incómodos debates existentes sobre el tema.

El universo y la humanidad son tan cambiantes que advertimos con el presente escrito nuestra preocupación ya manifestada porque se comience a presentar con frecuencia esta situación y se convierta en caos el ordenamiento jurídico y peor aún, no se cumpla el principio de seguridad jurídica.

Por ello, se hace necesaria la reforma o modificación del artículo 212 del Código Penal, en aras de proteger el principio de Igualdad ya que si este antecedente continúa así, los bienes jurídicos tutelados continuarán recibiendo una desigual protección

No es capricho nuestro hablar sobre este tema puesto que la Litis no se centra solamente en acceso carnal violento, el error no está en este delito, también se encuentra en las múltiples modalidades de acceso carnal a las que hicimos referencia precedentemente. Así mismo, existen muchos otros factores descompensados como consecuencia de esa acción ofensiva y devastadora como el honor, el pudor, la dignidad, integridad, libertad, fe, espiritualidad, relaciones interpersonales, entre otras.

Finalmente, nuestro único fin altruista pretendido es que cuando se presenten estas conductas, no existan yerros en la interpretación y mucho menos se considere que no se encuentran establecidas en la ley, distinto es que no se presenten con frecuencia. Miramos con desasosiego que el juez de conocimiento fehacientemente contemple la posibilidad de la atipicidad, no estaría siendo eficaz la estructura del Sistema Penal Acusatorio colombiano y se estarían ignorando los principios y valores que nuestra Constitución Política comprende ampliamente.

\section{REFERENCIAS BIBLIOGRÁFICAS}

Agudelo, N. (2010). Casos y preguntas de Derecho penal. Cuarta edición. Bogotá, Colombia: Temis.

Argentina. Ley 11.179/1984. Por la cual se expide el Código Penal de la Nación Argentina. Barrera, H. (1963). Delitos sexuales. Bogotá, Colombia: Temis.

Carnevali, R. (Abril, 2001). La mujer como sujeto activo en el delito de violación. Un problema de interpretación teleológica. Gaceta Jurídica, (250).

Chile. Comisión redactora del Código Penal de la República de Chile (12 de noviembre de 1874). Condenan a diez años de cárcel a maestra embarazada de alumno (2017, enero 14)
EI Tiempo Recuperado de: http-//wwweltiempo com/mundo/eeuu-y-canada condenan-alexandria-vera-maestra-embarazada-por-un-alumno-47729.

Congreso de Colombia. Ley Ordinaria 599/2000. 24 de julio, por la cual se expide el Código Penal, Diario Oficial 44097.

Corte Constitucional Sala Plena Sentencia C-059/10 (03 de febrero). Magistrado Ponente, Dr. Humberto Sierra Porto. Bogotá, D.C. Colombia.

Dagistrado ponente, Dr. Carlos Gaviria Díaz. Bogotá, D.C. Colombia.

Diccionario de la Lengua Española. Real Academia Española (2001). Acceso. Editoria Espasa.

Garofalo, R. (2005). La Criminología: Estudio sobre el delito y la teoría de la represión. R. Editorial BdeF.

Garrido, M. (2005). Derecho Penal Parte especial. Vol. 2. Chile: Editorial Jurídica de Chile. Orts, E. (1995). Delitos contra la libertad sexual. Valencia: Editorial Tirant lo Blanch. Panamá. Ley 14 (2007, 18 de mayo). Por la cual se expide el Código Penal de la República de Panamá. Asamblea Nacional.

Perú. Decreto Legislativo 635. (08 de abril de 1991). Por el cual se promulga el Código Penal del Estado Peruano.

Porte, P., Candaudap, C. (1991). Apuntamientos de la Ciudad de México, México: Editorial Porrúa.

Tres mujeres accedieron de manera carnal a un hombre para robarle su esperma. (2015, mayo 14). Recuperado de: http://tac3news.com/tres-mujeres-accedieron-de-manera-carnal-a-un-hombre-para-robarle-su-espermal. 